\title{
MORPHOLOGICAL IDENTIFICATION OF MALARIA VECTORS WITHIN ANOPHELESSPECIES AT HADEJIA AND JAHUN
}

\author{
Ahmed, U.A. \\ Department of Medical Laboratory Services, Jahun General Hospital, Jigawa, Nigeria. \\ umaradamuahmed@yahoo.com
}

\begin{abstract}
This study was carried out between May and October, 2011 to morphologically identify Anopheles species in parts of Jigawa State. Using Anopheles characteristics as described by Gilles and Coetzee (1987) using Zeiss light microscope at $x$ 20. A total of 3027 Anopheles were collected and identified. 3027 (78.40\%) were collected from Hadejia Local Government Area while 834 (21.60\%) were collected from Jahun Local Government Area. Using Anopheles characters of Gilles and Coetzee (1987) under zeiss light microscope, 2605 (67.47\%) were Anopheles gambiae s.l., 907 (23.49\%) were Anopheles funestus and 349 (09.04\%) were Anopheles maculipalpis. Hadejia Local Government Area had the higher number of Anopheles identified. An. gambiae s.l. ranked the highest among other species. Further molecular identification of sub-species complex of An. gambiae s.l. and An. funestus is strongly recommended in the area.
\end{abstract}

Keywords: Morphological, malaria, vectors, Anopheles, species.

\section{INTRODUCTION}

Malaria remains a leading cause of morbidity and mortality worldwide with an estimated 500 million cases and 2.5 million deaths annually (Stauffer, 2003). Anopheles gambiae s./ and An. funestus transmit the Plasmodium parasites in sub-saharan Africa among the human population. Determination of risk of malaria transmission requires quick and accurate methods of identification of Anopheles mosquitoes especially when targeting vector control (Maxwell et al., 2003).

Anopheles mosquito transmits malaria. The most important vectors of malaria are members of Anopheles s./ (complex), a group of morphologically identical yet genetically and behaviorally distinct species that differ markedly in their ability to transmit the diseases (Coluzzi, 1978). Members of the species complex include $A n$. gambiae s.s, An. arabiensis, An. merus, An. melas, An. bwambe, and $A n$. quadrimaculatus (Coetzee et al., 2000).

Anopheles mosquitoes breed in areas with water bodies such as ponds, rivers, surface water, wastewaters, well, etc (Service, 1980). Moreover, the study areas are suitable for the growth and development of various strains of mosquitoes as ponds, wells and surface water bodies of different sizes are available during rainy season, May to October and supplemented waste-water throughout the year which could also serve as breeding sites (Zakari, 2006).

Molineaux and Grammicia (1980) concluded that differences in Anopheles species cause the failure of insecticide application and mass drug administration in suppressing malaria transmission. The present Anopheles status of the study areas needs to be updated Therefore, the aim of this study is to identify various Anopheles species in the area for effective vector control.

\section{MATERIALS AND METHODS}

Study Area

The study was carried out in Hadejia and Jahun Local Government Areas of Jigawa State, Nigeria between May and October, 2011. The area is situated on latitude $11^{\circ} 31^{\prime} \mathrm{N}$ and longitude $9^{\circ} 09^{\prime} \mathrm{E}$. It falls within the Sudan savannah zone, it is semi arid region. The minimum and maximum temperature range between $15.89^{\circ} \mathrm{C}$ and $36^{\circ} \mathrm{C}$ and fall as low as $10^{\circ} \mathrm{C}$ during harmattarn season between December and February. Rainfall ranges form $491 \mathrm{~mm}$ to $1186 \mathrm{~mm}$ and starts from May and ends in October, while dry season starts in November and ends in April (Wikipedia, 2010). More water bodies that harbor survival of various strains of Anopheles are observed in the area.

\section{Sample Collection}

Indoor Collection

Indoor resting adult mosquitoes were collected according to the protocol of Molineaux and Grammiccia (1980). The collection was achieved by Indoor Residual Spray (IRS) technique. The selected houses were visited between 6 am and 10am every other day for ten days. A sheet of large white cloth $(4 \mathrm{~m} \times 3 \mathrm{~m})$ was spread on the floor in a room for easy recognition of mosquitoes and this was followed by spray of pyrethrum (Pyrethrin). After 15 minutes, the mosquitoes that fall on the sheet were collected and stored separately in Eppendorf tubes containing anhydrous calcium sulphate $\left(\mathrm{CaSO}_{4}\right)$ as drying agent until required (Molineaux and Grammiccia, 1980). Thirty six houses were visited in this study.

\section{Collection and Rearing of Larvae}

Larval sampling was done using the standard dipping method with a $350 \mathrm{ml}$ mosquito scoop (Bioquip, Gardena, CA, USA) as described by Service (1993) and this took twenty days. The larvae were immediately preserved in plastic jugs and taken to laboratory for rearing according to WHO (1975a and 1975b). 
They were kept at room temperature and fed with ground fish diet powder in Aquarium. The adults that emerged (within 1-4 days) were killed by anaesthetizing using drops of Acetyl acetate placed on large Whatman's filter paper above the adults container. They were collected and stored separately in Eppendorf tubes prior to identification.

\section{Morphological Identification of Anopheles Mosquitoes}

Using morphological characters of Gilles and Coetzee (1987) under $\times 20$ Zeiss light microscope. The identification focused on dark spot at the upper margins of the wings which is common to all Anopheles. The palpis are elongated and segmented into three. A pale spot on second dark area, a light spot between the two dark spots on vein 6 and absence of fringes on vein 6 are features for Anopheles funestus. Speckles on the legs, third preapical dark area on vein 1 with a pale interruption and tersus 1-4 with conspicuous pale bands are features for Anopheles gambiae. Vein 1 with 2 accessory sector pale spots, hind tarsi 4 and 5 entirely pale and legs are pale are features for Anopheles maculipalpis.

\section{Data Presentation}

The data obtained on Anopheles species in the study area was expressed in percentage and presented in tables.

\section{RESULTS}

A total of 3861 Anopheles were identified of which 3027 (78.40\%) and $834(21.60 \%)$ were collected from Hadejia and Jahun Local Government Areas respectively.

Anopheles gambiae s.l were 2605 (67.47\%), An. funestus were 907 (23.49\%) and An. maculipalpis were $349(09.04 \%)$. The adults collected indoors from Hadejia were 1812 (59.86\%) while 1215 (40.14\%) were reared from larvae. Adults collected indoors from Jahun were 603 (72.30\%) while 231 (27.70\%) were adults reared from larvae.

Table 1 shows the number of adult Anopheles species collected from Hadejia Local Government Area. In this, 3027 (78.40\%) Anopheles species were identified of which $1812(59.86 \%)$ were collected indoors; of this $116(61.59 \%)$ were An. gambiae s.l, 495 (27.32\%) were An. funestus and 201 (11.09\%) were An. maculipalpis while 1215 (40.14\%) were adults reared from larvae; 902 (74.24\%) were An. gambiae s.l, 231 (19.01\%) were An. funestus and 82 (6.75\%) were $A n$. maculipalpis.

Table 2 shows the Anopheles distribution collected from Jahun Local Government Area. The overall collection was 834 (21.60\%). Of this, 603 (72.30\%) were adults collected indoors; $401(66.50 \%)$ were $A n$. gambiae s.l, 143 (23.72\%) were An. funestus and 59 (09.78\%) were An. maculipalpis while 231 (27.70\%) were adults reared from larvae; $186(80.52 \%)$ were An. gambiae s.l., 38 (16.45\%) were An. funestus and $07 \quad(03.03 \%)$ were An. maculipalpis.

Table 1: Distribution of Adult Anopheles species collected at Hadejia Local Government Area

\begin{tabular}{|c|c|c|c|}
\hline Anopheles species & Adults collected indoors & $\begin{array}{l}\text { Adults reared from } \\
\text { larvae }\end{array}$ & Overall \\
\hline An. gambiae s.I & 1116 & 902 & 2018 \\
\hline An. funestus & 495 & 231 & 726 \\
\hline An. maculipalpis & 201 & 82 & 283 \\
\hline Total & 1812 & 1215 & 3027 \\
\hline
\end{tabular}

Table 2: Distribution of Adult Anopheles species collected at Jahun Local Government Area.

\begin{tabular}{|c|c|c|c|}
\hline Anopheles species & Adults collected indoors & $\begin{array}{l}\text { Adults reared from } \\
\text { larvae }\end{array}$ & Overall \\
\hline An. gambiae s./ & 401 & 186 & 587 \\
\hline An. funestus & 143 & 38 & 181 \\
\hline An. maculipalpis & 59 & 07 & 66 \\
\hline Total & 603 & 231 & 834 \\
\hline
\end{tabular}

\section{DISCUSSION}

Identification of Anopheles species like all other mosquitoes is changing where taxonomists are rather describing new species and subspecies or redescribing existing one. Many techniques used in the identification of Anopheles mosquitoes have been published including Faran (1981) and Gillet (1972). This study had revealed the abundance of $A n$. funestus, An. gambiae s./ and An. maculipalpis in a large number (Table 1\&2). Most of the Anopheles reported in this study was An. gambiae s.l. The most important vector of malaria in sub-Saharan Africa is An. gambiae s./ and it exhibits extreme heterogeneity (Coluzzi et al., 2002).
The result of morphological examination of adults reared from larvae and collected indoors has revealed the presence of predominantly An. gambiae s./ (Table 1 and 2). This observation is important; as it reveals that $A n$. gambiae and other species are breeding in the study area. Spraying insecticides can reduce vector infectivity by reducing the vector survival rate and increasing the length of the sporogonic cycle (Anonymous, 1991). For example, when indoor resting mosquitoes are forced to rest outside, where ambient temperature is suboptimal for parasite maturation and eventual vector survival (Lines et al., 1991). 
Hadejia Local Government area had higher number of Anopheles 3027 (78.40\%) (Table 1); this may be due to the fact that it has more mash areas as when compared with Jahun. Service (1980); as some of the environmental management practices to include reduction and or management of breeding sites by filling container receptacles, water storage jars, village pot, tyres, canoes, and abandoned cans. Breeding sites like ponds burrow pits, fresh and salt mashes can be drained or impoundments built, which could lead to permanent control.

The study had also revealed the abundance $A n$. funestus and An. maculipalpis in relatively low proportion in Jahun Local Government Area (Table 1) than in Hadejia Local Government Area. Similarly, the adults collected indoors, 2415 (62.55\%) is higher than the adults reared from larvae, $1446(37.45 \%)$ and this had agreed with findings of Ahmed et al. (2011)

\section{REFERENCES}

Ahmed, U.A and Ahmed, M.M (2011): Morphological Identification of Malaria Vectors within Anopheles Species in Parts of Kano State, Nigeria. Bayero Journal of Pure and Applied Sciences, 4 (2): 160 - 163.

Anonymous (1991): Malaria: Prospects and Obstacles, A report of the committee for the Study on Malaria Prevention and Control: Status Preview and Alternative Strategies. Division of International Health, Institute of Medicine, National Academic Press Washington D.C., 1991: $157-179$.

Coetzee, M.C. (2000): Distribution of African Malaria Mosquitoes Belonging to the Anopheles gambiae complex. Parasitology Today, 16: 74 $-77$.

Coluzzi, M. (1978): Morphological Divergencies in the Anopheles gambiae complex. Rivista, Malariolagia, 43: 197 - 232.

Coluzzi, M., Sabbatini, A., Della-Tore, DiDeco, M.A. and Petrarca, V. (2002): A Polythene Chromosome Analysis of the Anopheles gambiae Species Complex. www.scienceexpress.org./3otcober,2002page 1.11//26/science/077769.

Faran, M.B. (1981): Synonym of Anopheles with An. evansi with Description of Male Genitalia of Lectotype of An. evansi, Mosquitoes Systematic, 13 (1): $86-91$

Gillet, J.D. (1972): Common Africa Mosquitoes and their Medical Importance. Willem Heimann Medical Books Ltd., London, Pp 1 - 37.

Lines, J.D., Wilkes, T.Y., Lyimo, E.M. (1991): Human Malaria Infectiousness measured by Age- whereby 592 Anopheles were collected indoors while 579 were reared from larvae and this may be attributed to errors associated with larval rearing.

\section{CONCLUSION}

The result of morphological identification of malaria vectors within Anopheles species in this study justifies the presence of $A n$. funestus, An. maculipalpis and $A n$. gambiae $s$./ in the study area.

\section{RECOMMENDATION}

Further molecular characterization of the Anopheles identified into An. arabiensis, An. gambiae s.s, M and $\mathrm{S}$ forms, the species complex of $A n$. gambiae s.l and same on An. funestus species need to be carried out, since morphological identification is a preliminary stage.

specific sporozoites Rate $A n$. gambiae in Tanzania Parasitology; 2:167 - 177.

Maxwell, A.A., Kwabena, M.B., Samuel D., Uri, S.M., Isacc, A., Elizabeth, D., Daniel, E.S., William, O.R., Kwadwo, K., David, J.F. (2003): Detection of Malaria Sporozoites by Standard ELISA and Vec-Test ${ }^{T M}$ Dip-stick Assay in Field-Collected Anopheline Mosquitoes from a Malaria Endemic Site Ghana. Tropical and International Health, 8 (II): 1012 - 1017.

Molineaux, L. and Grammicia, C. (1980): The Garki Project: Research on Epidemiology and Control Malaria in the Sudan Savannah of West Africa. WHO, Geneva, Pp 311.

Service, M.W. (1980): A Guide to Medical Entomology, Macmillan International College Edition. Oxford Press Ltd., Pp $23-45$.

Service, M.W. (1993): Field Sampling Method, $2^{\text {nd }}$ edition, Elsevier Applied Science, London. Pp $12-73$.

Stauffer, W.M. (2003): Special Challenges in the Prevention and Treatment of Malaria in Children. Current Infectious Disease Report (5) $45-53$.

Tripet, F., Taylor, C.E., Norris, D.E., and Lanzaro, C. (2001): DNA Analysis if Transferred Sperm Reveals Significant Levels of Gene Flow Between Molecular Forms of the Anopheles gambiae. Molecular Ecology, 10: 1725 1732.

Wikipedia, (2001): www.wikipedia.org 17/October, 2010.

WHO (1975a, and 1975b): Manual Practical Entomology in Malaria. Geneva, WHO Offset Publication No. 13 (1975a), Part I: Pp 145 160. 